\title{
Hyperaminoacidaemia reduces insulin-mediated glucose disposal in healthy man
}

\author{
P. Tessari, S. Inchiostro, G. Biolo, E. Duner, R. Nosadini, A. Tiengo and G. Crepaldi \\ Cattedra di Patologia Medica $1^{\text {a }}$ e di Malattie del Ricambio, University of Padova, Padova, Italy
}

\begin{abstract}
Summary. To determine whether hyperaminoacidaemia may modify insulin-mediated glucose disposal, normal subjects were studied with the euglycaemic glucose-clamp technique, with or without an amino acid infusion, at a rate sufficient to duplicate the plasma concentration of most amino acids. Steady-state glucose infusion rates to maintain euglycaemia were $36 \%$ lower during hyperaminoacidaemia $(7.3 \pm 1.0$ ver-
\end{abstract}

sus $\left.11.4 \pm 0.8 \mathrm{mg} \cdot \mathrm{kg}^{-1} \cdot \mathrm{min}^{-1}, p<0.01\right)$ at comparable insulin concentrations ( $92 \pm 6$ versus $93 \pm 7 \mathrm{mU} / 1$ respectively). Thus, under conditions of hyperinsulinaemia, amino acids could compete with glucose as metabolic fuels.

Key words: Hyperaminoacidaemia, euglycaemic hyperinsulinaemic clamp, glucose disposal.
During an euglycaemic, hyperinsulinaemic clamp, insulin-sensitivity is often expressed as the glucose infusion rate necessary to maintain euglycaemia [1]. However, many other metabolic changes occur under hyperinsulinaemic conditions. Among them, plasma free fatty acid, ketone body and amino acid concentrations decrease markedly. Since competition between substrates as metabolic fuels may occur [2], glucose uptake in vivo could be indirectly enhanced by the concomitant decrease in concentration and utilization of other substrates. Therefore, "insulin sensitivity", measured with the euglycaemic, hyperinsulinaemic clamp technique, could be modified by preventing the fall and/or increasing the concentrations of the substrates suppressed by insulin.

Recently, increased plasma free fatty acid concentrations have been shown to reduce insulin-mediated glucose disposal [3]. However, it is not known whether in vivo increments in plasma amino acid concentrations may also affect glucose disposal rates. Therefore, the aim of the present study was to evaluate the effect of hyperaminoacidaemia on insulin-mediated glucose utilization in postabsorptive normal subjects.

\section{Subjects and methods}

Healthy subjects (aged 21-57 years) were studied in the post-absorptive state. All subjects had normal body weight, and consumed their usual weight-maintaining diet $(\sim 30 \mathrm{kcal} / \mathrm{kg}$ per day, containing $50 \%$ of total calories as carbohydrates, $20 \%$ as protein and $30 \%$ as fat) for at least 3 days prior to the study. The details and the potential risks of the study were explained, and each subject signed an informed written consent before the initiation of the study. The subjects were divided into two groups. In group A, (five males, one female, age: $28 \pm$ 3 years, body mass index: $22.9 \pm 0.8$ ), an euglycaemic-hyperinsulinaemic clamp was performed for $180 \mathrm{~min}$, as previously described [4]. Insulin was infused by means of a Harvard Pump (Harvard Apparatus, Millis, MA, USA), at the rate of $0.05 \mathrm{U} \cdot \mathrm{m}^{2-1} \cdot \mathrm{min}^{-1}$. Blood glucose concentration was maintained by means of the Biostator (Miles Laboratories, Elkhart, IN, USA) [4] at $4.72 \pm 0.11 \mathrm{mmol} / \mathrm{l}$ (coefficient of variation: $\sim 11 \%$ ). In group $B$ (four males, one female, age: $35 \pm$ 5 years, body mass index: $22.0 \pm 0.7)$ the subjects were studied as for group A, with the addition of an amino acid infusion for the same duration of the insulin infusion. Blood glucose concentration was clamped at $4.89 \pm 0.06 \mathrm{mmol} / 1$ (coefficient of variation: $\sim 11 \%$ ). The amino acid mixture contained $84.3 \mathrm{mmol} / 1 \mathrm{~L}$-alanine, $34.5 \mathrm{~L}$-arginine, 6.1 L-phenylalanine, 120 glycine, $68.7 \mathrm{~L}$-isoleucine, $15.5 \mathrm{~L}$-istidine, 83.4 L-leucine, 41.6 L-lysine, 6.7 L-methionine, 69.6 L-proline, 47.6 Lserine, $37.8 \mathrm{~L}$-threonine, $3.7 \mathrm{~L}$-tryptophane and $71.8 \mathrm{~L}$-valine. The amino acid solution was infused by means of Harvard Pumps, corresponding to a total infusion rate of $976 \mu \mathrm{mol} / \mathrm{min}$. No priming dose was administered. Arterialized blood samples [4] were taken in the basal state, then every $30 \mathrm{~min}$ from 0 to $150 \mathrm{~min}$, and every $10 \mathrm{~min}$ during the last $30 \mathrm{~min}$ of the study. Plasma glucose [4], insulin [4], glucagon [5] and amino acid concentrations [6] were determined on each sample. The glucose infusion rate to maintain euglycaemia (M), expressed as $\mathrm{mg} \cdot \mathrm{kg}^{-1} \cdot \mathrm{min}^{-1}$, was calculated from the flowchart of the Biostator. The " $M$ " values, as well as plasma insulin and amino acid concentrations during the clamp studies reported in the tables, correspond to the mean values of the last $30 \mathrm{~min}$ of the infusions.

All results are expressed as mean \pm SEM. Statistical analyses were performed using two-tailed Student's t-tests for paired data (changes from the corresponding baseline) and for unpaired data (differences between groups). A $p$ value equal or less than 0.05 was considered statistically significant. 
Table 1. Plasma concentrations of selected amino acids at basal and at plateau (150-180 min) during euglycaemic hyperinsulinaemic clamp studies without (Group A) or with amino acid infusion (Group B)

\begin{tabular}{lrrrrr}
\hline & \multicolumn{2}{l}{ Group A } & & \multicolumn{2}{c}{ Group B } \\
\cline { 2 - 3 } \cline { 5 - 6 } & \multicolumn{1}{c}{ Basal } & Plateau & & Basal & Plateau \\
\hline Lysine $(\mu \mathrm{mol} / \mathrm{l})$ & $239 \pm 43$ & $174 \pm 31$ & & $267 \pm 13$ & $397 \pm 30$ \\
Leucine & $130 \pm 8$ & $57 \pm 5$ & & $108 \pm 8$ & $238 \pm 32$ \\
Isoleucine & $66 \pm 5$ & $22 \pm 2$ & & $52 \pm 4$ & $183 \pm 25$ \\
Phenylalanine & $90 \pm 10$ & $53 \pm 7$ & & $70 \pm 3$ & $56 \pm 5$ \\
Valine & $233 \pm 13$ & $130 \pm 10$ & & $221 \pm 16$ & $459 \pm 43$ \\
Alanine & $256 \pm 23$ & $233 \pm 17^{\mathrm{a}}$ & & $319 \pm 37$ & $493 \pm 30$ \\
Glycine & $248 \pm 23$ & $179 \pm 32$ & & $264 \pm 36$ & $535 \pm 38$ \\
Serine & $88 \pm 15$ & $50 \pm 6$ & & $111 \pm 4$ & $164 \pm 11$ \\
\hline
\end{tabular}

All values at plateau were significantly different ( $p<0.01$ or less) from the corresponding values at basal, except for ${ }^{\mathrm{a}}$

Table 2. Plasma insulin and glucagon concentrations at basal and at plateau (150-180 $\mathrm{min}$ ), and glucose infusion rates to maintain euglycemia $(M)$, during the euglycaemic hyperinsulinaemic clamp studies without (Group A) or with (Group B) the amino acid infusion

\begin{tabular}{lccccc}
\hline & \multicolumn{3}{c}{ Group A } & & \multicolumn{2}{c}{ Group B } \\
\cline { 2 - 3 } & Basal & Plateau & & Basal & Plateau \\
\hline $\begin{array}{l}\text { Plasma insulin } \\
(\mathrm{mU} / 1)\end{array}$ & $9 \pm 1$ & $93 \pm 7$ & & $8 \pm 1$ & $92 \pm 6$ \\
$\begin{array}{l}\text { Plasma glucagon } \\
(\mathrm{pg} / \mathrm{ml})\end{array}$ & $138 \pm 34$ & $101 \pm 25^{\mathrm{b}}$ & $125 \pm 43$ & $136 \pm 44$ \\
$\begin{array}{l}\mathrm{M} \\
\left(\mathrm{mg} \cdot \mathrm{kg}^{-1} \cdot \mathrm{min}^{-1}\right)\end{array}$ & $/$ & $11.4 \pm 0.8$ & & $7.3 \pm 1.0^{\mathrm{a}}$ \\
\hline
\end{tabular}

${ }^{\mathrm{a}} p<0.01$ group $\mathrm{A},{ }^{\mathrm{b}} p<0.01$ basal

\section{Results}

Plasma amino acid and insulin concentrations, as well as glucose infusion rates to maintain euglycaemia, reached a steady-state after $60-90 \mathrm{~min}$ from the beginning of the clamp studies. In Table 1, plasma concentrations of selected amino acids in the basal state and in the last $30 \mathrm{~min}$ of the studies are reported. During the infusion of insulin alone, amino acid concentrations decreased markedly by $20-70 \%$ from basal, with the exception of alanine, which decreased only slightly. When the amino acid mixture was infused along with insulin, plasma concentration of most amino acids increased to a variable extent, reflecting their concentrations in the solution infused. Phenylalanine, which was infused in a reduced amount, decreased slightly but significantly from basal, probably because of hyperinsulinaemia and/or a stimulatory effect on whole-body protein synthesis and a consequent recruitment of this amino acid from the plasma pool. In Table 2, plasma insulin and glucagon concentrations in the basal state and during the hyperinsulinaemic clamps, as well as the glucose infusion rates to maintain euglycaemia (M), are reported.
Insulin concentrations were similar in the two groups both in the basal state and during the clamp studies. In contrast, $\mathrm{M}$ values were $36 \%$ lower $(p<0.01)$ in the group infused with amino acids. Plasma glucagon concentrations decreased by about 30\% during the infusion of insulin alone, but did not significantly change from basal when the amino acids were also infused.

\section{Discussion}

The present study demonstrates that hyperaminoacidaemia decreases the rate of glucose infusion necessary to maintain euglycaemia during hyperinsulinaemic clamp studies. This diminished requirement for exogenous glucose may reflect either its decreased peripheral uptake or an increased rate of endogenous production. As glucose turnover was not measured in the present studies, the relative contributions of these two possible effects cannot be determined. At plasma insulin concentrations of $90-100 \mathrm{mU} / 1$, endogenous glucose production is almost completely suppressed [1]. However, it is not known whether an "escape" from such a suppression will occur when gluconeogenic substrates, like most amino acids, are supplemented together with insulin. Therefore, further experiments will be required to answer these questions. It is conceivable, however, that the reduced " $M$ " values observed during the amino acid infusion may depend, at least in part, on competitions between glucose and amino acids as metabolic fuels [7]. Insulin has been shown to stimulate some amino acid transport systems in vitro across the cell membrane [8]. Thereafter, amino acids can be metabolized as Acetyl $\mathrm{CoA}$ and further oxidized through the Tricarboxylic Acid cycle. Therefore, they could substitute for other substrates, like glucose, as energy sources. A sparing effect by free-fatty acids on insulin-induced glucose uptake has recently been demonstrated in vivo [3], thus confirming Randle's hypothesis of a glucose-sparing effect by a variety of substrates mainly linked to lipid metabolism [2]. A similar effect can be postulated for the insulin-mediated uptake of amino-acids. As a 3-to 4-fold increment in glucagon concentration has been suggested to decrease forearm glucose uptake [9], a possible influence of the relatively higher glucagon concentration on the reduced glucose disposal observed during the amino acid infusion cannot be excluded. However, the difference in glucagon levels between the two groups were small. Therefore, a significant effect by glucagon itself seems to be unlikely.

The amino acid mixture used in the present study contained relatively high amounts of branched-chain amino acids and lower amounts of aromatic amino acids and methionine. Such solutions are currently used in the parentheral nutrition of patients with liver failure, a condition often associated to impaired glucose tolerance, insulin-resistance, hyperinsulinaemia and hyper- 
glucagonaemia [10]. As hyperinsulinaemia may be further increased by glucose and amino acids often infused in combination in these patients, a clinical situation similar to the experimental conditions of the present study is likely to occur. Therefore, our data suggest that hyperaminoacidaemia can further inpair glucose metabolism in these patients.

Finally, the infusion of $14.4 \mu \mathrm{mol} \cdot \mathrm{kg}^{-1} \cdot \mathrm{min}^{-1}$ of amino acids (corresponding to $\sim 0.23 \mathrm{mg} \cdot \mathrm{kg}^{-1} \cdot \mathrm{min}^{-1}$ of nitrogen) resulted in the "spare" of $22.8 \mu \mathrm{mol} \cdot \mathrm{kg}^{-1}$. $\min ^{-1}$ of glucose. This discrepancy, on a molar basis, between the amino acids infused and the decrease in glucose requirement, may have some tentative explanations. First, the Biostator may slightly overestimate the "M" values. Second, even if the total amount of Acetyl CoA theoretically produced by the oxidation of the amino acids infused is about half of that potentially derived from the glucose "spared" ( $\sim 23.8$ vs $\sim 45.6$ $\mu \mathrm{mol} \cdot \mathrm{kg}^{-1} \cdot \mathrm{min}^{-1}$, respectively), it should be borne in mind that amino acid oxidation also produces reduced coenzymes that can directly enter the respiratory chain, leading to ATP formation. Moreover, some of the Acetyl CoA residues from amino acid oxidation may enter the Tricarboxylic Acid cycle as four or five carbon atom compounds, thus increasing the theoretical number of amino acid-derived carbons entering the Tricarboxylic Acid cycle. Third, a significant endogenous glucose production despite hyperinsulinaemia, possibly mediated by an excess of gluconeogenic amino acids and/or by a relative hyperglucagonaemia, could also be considered.

Acknowledgement. This work was supported in part by Grants of the Consiglio Nazionale delle Ricerche of Italy $\left(\mathrm{n}^{\circ} 83.02857 .56, \mathrm{n}^{\circ}\right.$ 84.02551.56, Progetto Finalizzato Medicina Preventiva e Riabilitativa).

\section{References}

1. DeFronzo RA, Tobin JD, Andres R (1979) Glucose clamp technique: a method for quantifying insulin-secretion and resistance. Am J Physiol 273: E214-E223

2. Randle PJ, Newsholme EA, Garland PE (1964) Regulation of glucose uptake by muscle. 8 . Effects of fatty acids, ketone bodies and pyruvate, and of alloxan diabetes and starvation, on the uptake and metabolic fate of glucose in rat heart and diaphragm muscle. Biochem J 93: 652-665

3. Ferrannini E, Barret E, Bevilacqua S, DeFronzo RA (1983) Effect of fatty acids on glucose production and utilization in man. J Clin Invest 72: 1737-1747

4. Nosadini R, Del Prato S, Tiengo A, Valerio A, Muggeo M, Opocher G, Mantero F, Duner E, Marescotti MC, Mollo F, Belloni F (1983) Insulin resistance in Cushing's Syndrome. J Clin Endocrinol Metab 57: 906-910

5. Faloona GR, Unger RF (1974) Glucagon. In: Jaffe BM, Behrmann HR (Eds) Methods of hormone radioimmunoassay. Academic New York, pp 317-330

6. Marescotti MC, Trevisan R, Avogaro A (1985) Determinazione degli amino acidi plasmatici mediante cromatografia liquida ad alta pressione. G Med Lab 12: 9-12

7. Schwenk WF, Haymond MW (1984) Decreased forearm uptake of glucose during amino acid infusion. Diabetologia 27: 33 (Abstract)

8. Guidotti GG, Borghetti AF, Gozzola GC (1978) The regulation of amino acid transport in animal cells. Biochim Biophys Acta 515: 329-366

9. Schneider SH, Fineberg SE, Blackburn GL (1981) The acute metabolic effects of glucagon and its interactions with insulin in forearm tissue. Diabetologia 20:616-624

10. Riggio O, Merli M, Cangiano C, Capocaccia R, Cascino A, Lala A, Leonetti F, Mauceri M, Pepe M, Rossi Fanelli F, Savioli M, Tamburrano G, Capocaccia L (1982) Glucose intolerance in liver cirrhosis. Metabolism 31: 627-634

Received: 20 August 1985

and in revised form: 28 September 1985

Dr. Paolo Tessari

Cattedra di Malattie del Ricambio

Istituto di Medicina Clinica

Policlinico Universitario

Via Giustiniani 2

I-35100 Padova

Italy 